\title{
КОНЦЕПЦИЯ РОСТА ПРОИЗВОДИТЕЛЬНОСТИ В РОССИЙСКОЙ ФЕДЕРАЦИИ
}

\begin{abstract}
АНнотАЦия. Обосновано значение роста производительности для экономического развития и социального прогресса. Проанализирована динамика производительности труда в целом по экономике Российской Федерации. Выделены цели концепции роста производительности в Российской Федерации и раскрыто их содержание. Дано обоснование формирования единого понимания понятийного аппарата, обозначены подходы и методы расчета производительности, новые принципы организации деятельности по повышению производительности, изменения в учет и реализацию факторов, влияющих на повышение производительности. Предложен комплекс мероприятий по организации работы по повышению производительности на различных уровнях управления и основные направления формирования государственной программы.

кЛЮЧЕВЫЕ СЛОВА. Производительность; концепция роста производительности; методы расчета производительности; факторы повышения производительности; государственные программы повышения производительности.

ИНФОРМАЦИЯ О СТАТЬЕ. Дата поступления 28 марта 2017 г.; дата принятия к печати 14 апреля 2017 г.; дата онлайн-размещения 21 июня 2017 г.
\end{abstract}

L. G. Sokolova

Baikal State University,

Irkutsk, Russian Federation

\section{CONCEPTION OF PRODUCTIVITY INCREASE IN THE RUSSIAN FEDERATION}

\begin{abstract}
The article substantiates the significance of increase in productivity for economic development and social progress. It analyses the dynamics of labor productivity in the Russian Federation economy on the whole. It specifies the goals of the productivity growth conception in the Russian Federation and reveals its content. It brings forth the grounds of developing a uniform understanding of the conceptual framework, identifies the approaches and methods of calculating productivity, the new principles of activity arrangement in increasing productivity the changes in recording and implementing the factors that influence the increase in productivity. The article offers a complex of measures in activity management of increasing productivity at various managerial levels and main directions of developing the governmental program. KEYWORDS. Productivity; conception of increase in productivity; methods of calculating productivity; factors of productivity increase; governmental programs of productivity increase.
\end{abstract}

ARTICLE INFO. Received March 28, 2017; accepted April 14, 2017; available online June 21, 2017.

Значение роста производительности как основного источника увеличения национального богатства страны и благосостояния ее населения признано во всем мире. В периоды кризисных явлений в экономике большинство зарубежных стран (государства Западной Европы, Япония, США) большое внимание уделяли повышению производительности, что способствовало успешному преодолению экономических трудностей. Для РФ в период развития рыночных отношений эта проблема стано-

\section{Baikal Research Journal}


виться особенно актуальной. В ходе реформирования системы управления страной основной упор делается на перераспределение функций и ресурсов между федеральным центром и местными органами, решение проблем не в сфере непосредственного производства, где закладываются основы наращивания добавленной стоимости, а в сфере обращения. Такой подход к реформированию и структурированию экономики страны не акцентирует внимание на повышении производительности, без чего невозможен рост эффективности экономики, развитие личности работников, решение социальных задач в масштабе предприятия, региона и в целом РФ.

Динамика показателя производительности акцентирует внимание на основных факторах экономического роста, уровне жизни населения, улучшении национального платежного баланса, сдерживании роста инфляции, а в конечном итоге, это отражает уровень заработной платы, соотношение цены и издержек производства, объемы капитальных вложений и занятость населения. Российская экономика дает наглядный пример взаимоувязки показателей, обуславливающих развитие производства и производительности.

Анализ статистических данных выявил стабильное снижение темпов прироста производительности труда как в целом по экономике РФ, так и по видам экономической деятельности (табл. 1).

Диналика производительности труда

Таблица 1 в целом по экономике Российской Федерации

\begin{tabular}{|c|r|}
\hline Год & Производительность труда, \% к предыдущему году \\
\hline 2003 & 107,0 \\
\hline 2004 & 106,5 \\
\hline 2005 & 105,5 \\
\hline 2008 & 104,8 \\
\hline 2009 & 95,9 \\
\hline 2010 & 103,2 \\
\hline 2013 & 101,8 \\
\hline 2014 & 100,9 \\
\hline 2015 & 96,8 \\
\hline
\end{tabular}

Составлено по данным: URL: http://www.gks.ru/wps/wcm/connect/rosstat_main/rosstat/ru/ statistics/efficiency/\#.

Это отразилось на развитии видов экономической деятельности и заработной платы работников. Индекс промышленного производства в январе - феврале 2017 г. по сравнению с соответствующим периодом 2016 г. составил 99,7\%, в феврале 2017 г. по сравнению с февралем 2016 г. - 97,3 \%. По состоянию на 1 марта 2017 г. суммарная задолженность по заработной плате по кругу наблюдаемых видов экономической деятельности выразилась в 3613 млн р. и по сравнению с 1 февраля 2017г. увеличилась на 381 млн р. (на 11,8 \%). Наивысший уровень задолженности по заработной плате отмечен у работников обрабатывающих производств (46\%), в строительстве $(22 \%)$, сельском хозяйстве (8\%), в обеспечении электрической энергией, газом и паром (6\%), на транспорте (5\%)

Поскольку повышение производительности направлено на снижение затрат при достижении конечной цели, то оно тесно взаимоувязано не только с показателями ценообразования, но и с развитием сбыта продукции и услуг на внутреннем и внешнем рынках, загрузкой производственных мощностей, капиталловооруженностью, развитием инвестиционных процессов.

${ }^{1} \mathrm{O}$ промышленном производстве в январе-феврале 2017 года / Росстат. URL: http://www.gks.ru/ bgd/free/B04_03/IssWWW.exe/Stg/d02/51.htm.

\section{Baikal Research Journal}

электронный научный журнал Байкальского государственного университета 
Влияние производительности на реальный экономический рост и социальный прогресс отражены в национальных докладах развивающихся стран. В мировом сообществе создана и, функционирует, формируемая с 1944 г. Международной организацией труда (МОТ), система движения за производительность, базирующаяся на четырех принципах:

- труд не является товаром;

- бедность, где бы она не проявлялась, представляет опасность для всеобщего процветания;

- свобода выбора и ассоциаций необходимы для поддержания прогресса;

- борьба с нуждой должна вестись активно в каждой стране, путем постоянных и согласованных международных усилий.

Впервые концепцию производительности разработали в США, положив в основу принципы низкозатратной продукции и массового производства потребительских товаров при высокой покупательной способности. Включение в движение за производительность Англии и стран Западной Европы переместило внимание в концепции производительности с идеи повышения физического объема производства на новую концепцию производительности - обеспечение выпуска продукции с наименьшими затратами. В разработанной в 1958 г. Комитетом по производительности Европейской организации производительности Концепции учтен уже психологический фактор, т. е. значение общественного мнения, социальные условия и мораль населения.

Проведенная организационная работа в США и странах Западной Европы по повышению производительности и оказанное ею влияние на развитие экономики распространило опыт деятельности этих стран по всему миру. В 60-х гг. XX в. была создана Азиатская организация производительности, объединившая 8 стран данного континента. В 70-х гг. XX в. созданы - Европейская ассоциация национальных центров производительности (16 стран) и Европейская Федерация услуг по производительности (11 стран). В 90-е гг. ХХ в. появились центры производительности в странах социалистического лагеря Центральной и Восточной Европы, а также была создана Всеафриканская организация производительности (9 стран).

Обобщая опыт стран по стабилизации, восстановлению и развитию экономики, реальному росту национального дохода отмечено, что повышение производительности во всех сферах общественной жизнедеятельности рассматривалось как необходимое условие и главная цель экономической политики.

Вхождение России партнером в мировое сообщество стран с рыночной экономикой требует единого понимания развития экономических процессов и содержание понятия «производительность», направлений деятельности по повышению производительности, оценочных критериев и показателей. Для российской экономики формирование нового подхода к проблемам повышения производительности обусловлено еще и тем, что в послереволюционной России была создана своя, отличная от зарубежной, концепция коренного различия между капиталистической и социалистической организацией труда [1].

Основным моментом при формировании концепции роста производительности труда в современной России является формирование единого понимания проблемы повышения производительности. В новых условиях хозяйствования важно раскрыть новые подходы к понятию «производительность», определить основные направления и методы повышения производительности, обозначить организационные составляющие деятельности на различных уровнях управления.

Определение содержания понятия «производительность» на современном этапе обусловлено тем, что к его раскрытию советские и зарубежные ученые подходили с позиций социалистической и капиталистической экономической теории.

\section{Baikal Research Journal}


Зарубежные экономисты в затраты производства кроме стоимости материалов, оплаты услуг, амортизации, прибыли включают расходы на рабочую силу. Это позволяет определять производительность капитала, производительность затрат энергии, производительность материалов, производительность труда и т. д. В советской теории экономики труда затраты на рабочую силу не рассматривались в качестве частного показателя производительности, так как считалось, что рабочая сила при социализме не имеет стоимости, поэтому вместо производительности труда применялся показатель выработки продукции на одного рабочего, не рассчитывалась производительность работников, занимающихся умственным трудом, а использование вложенного капитала рассматривалось по методикам не связанных с показателями эффективности трудового потенциала.

Современные представления о теоретических подходах к определению и методам расчета производительности в российской литературе отличаются разнообразием и расплывчатостью понятий [2-4]. Несмотря на то, что Федеральной службой государственной статистики РФ введены кардинальные изменения в методику расчета производительности труда ${ }^{2}$, в практической деятельности продолжают использовать метод расчета производительности труда существовавший в советский период ${ }^{3}$.

МOT рассматривает производительность как умелое использование не только труда, но и всех ресурсов: капитала, основных фондов, материалов, времени, информации, энергии. Таким образом, производительность определяет взаимосвязь между конечными результатами и затратами на их достижение [1]. В зарубежной практике наиболее известны подходы к измерению производительности доктора К. Куросавы - профессора технологического института г. Токио [5]. Индивидуальную производительность он предлагает измерять на основе структуры рабочих часов, а общую производительность - по структуре стоимости произведенной продукции и видов добавленной стоимости.

Современная методика определения показателей производительности труда в РФ в основу расчета берет не стоимостной объем произведенной продукции, а показатель вновь созданной стоимости. Индекс изменения производительности труда по экономике в целом рассчитывается как частное от деления индексов физического объема ВВП и индекса изменения совокупных затрат труда в эквиваленте полной занятости.

В смысловом аспекте новое понятие производительности отражает следующие основные моменты:

- переход от узкого понимания производительности только живого труда к более широкому - учитывающему затраты всех видов ресурсов, включая материальные, финансовые, трудовые и др.;

- отнесение затрат на производство товаров или услуг за определенный период времени не к произведенному объему товаров, а к результату деятельности [6];

- рассмотрение производительности во всех видах деятельности: производственной, управленческой, коммерческой, финансовой и т. п. [7];

- производительность относится к показателям, регулируемым на любом уровне управления - корпоративном, муниципальном, региональном, общегосударственном.

Поскольку высокая производительность прямо пропорционально связана с повышением качества трудовой жизни, ее измерение, применение различных ме-

\footnotetext{
${ }^{2}$ Об утверждении методики расчета показателя «Индекс производительности труда : приказ Федер. службы гос. статистики от 20 дек. 2013 г. № 492 // СПС «КонсультантПлюс».

${ }^{3}$ URL: http://www.up-pro.ru/specprojects/lidery.
}

\section{Baikal Research Journal}


тодов расчета в условиях многоукладной экономики является для отечественной науки принципиально новой задачей.

В основе расчета показателей совокупной производительности на уровне федерации, региона или отрасли кроме валового внутреннего продукта (валового регионального продукта) могут использоваться показатели, заложенные в системе национальных счетов, чистый валовой продукт, прибыль. На различных уровнях управления необходимо использование и частных показателей производительности. Частные показатели производительности позволяют более точно измерить и эффективнее проконтролировать уровень и динамику использования различных ресурсов: финансовых, энергетических, материально-технических и т. п. Примером для корпоративного уровня управления может служить расчет производительности капитала, вложенного в производственный процесс изготовления продукции или предоставления услуг, рассчитываемый как отношение полученной добавленной стоимости (чистой продукции) или прибыли к стоимости основных (оборотных) фондов. Аналогичную систему расчета производительности капитала можно применить на федеральном или региональном уровнях управления. Важным обстоятельством является использование на разных уровнях управления сохранение сопоставимости и сводимости получаемых результатов. Иерархичная система показателей производительности должна включать общие и частные измерители затрат труда и других ресурсов сопоставимые при переходе от одного уровня управления к другому - от корпоративного уровня $\kappa$ региональному, а затем к федеральному. Сопоставимость и сводимость получаемых результатов по показателям производительности на разных уровнях управления и по различным показателям должна быть включена в государственную программу действий повышения производительности и проводиться в рамках международной практики учета и статистики в соответствии с требованиями развития рыночной экономики.

Новая концепция повышения производительности в РФ должна строиться на новых принципах организации данной деятельности.

К числу важнейших принципов следует отнести участие в повышении производительности всех категорий трудящихся, структур различных уровней управления и общественных организаций. Производительность выступает в качестве критерия измерения эффективности производственной деятельности, обеспечивая конкурентоспособность предприятий и учреждений на рынке товаров и услуг, увеличение объемов производства, вложение капитала на социальные нужды, что ведет к общему развитию экономики регионов и страны.

Вторым принципом новой концепции повышения производительности можно назвать обеспечение непрерывности данного процесса. Постоянный поиск путей повышения эффективности использования задействованных в производстве товаров и услуг ресурсов позволит гибко реагировать на изменения конъюнктуры рынка, изыскивать более рациональные формы и методы управления.

Следующий принцип новой концепции повышения производительности основан на системе справедливого распределения результатов повышения производительности между его участниками. В повышении производительности важна инициатива работников любого уровня управления - от высших менеджеров до рабочих. Ни высокотехнологичное оборудование, ни современные технологии не смогут обеспечить высокий уровень производительности без инициативы высококвалифицированного работника. Поэтому основополагающим фактором роста производительности японская школа по росту производительности считает рост производительности труда. И тогда на первый план выступают вопросы современной методологии работы с персоналом - внедрение новых форм участия работников в управлении предприятием (учреждением), справедливое распределение

\section{Baikal Research Journal}

электронный научный журнал Байкальского государственного университета 
прибыли между наемными работниками и собственниками капитала, стимулирования трудовой деятельности, повышение качества рабочей силы и т. п.

Новая концепция повышения производительности должна внести значительные изменения в учет и реализацию факторов, влияющих на обеспечение стабильных темпов ее роста.

В отечественной и зарубежной экономической литературе неоднократно приводились и дополнялись классификации факторов роста производительности. В общепринятом понимании все факторы делятся на внешние и внутренние. Влияние внешних факторов регулируется главным образом решениями и деятельностью органов государственного и муниципального управления.

Основными мероприятиями по реализации внешних факторов можно назвать создание законодательной и нормативно-правовой основы организации многоукладной производственно-хозяйственной деятельности, формирование инфраструктуры, основ инвестиционной политики, создание эффективной кредитной и налоговой системы и др. Повышение производительности труда невозможно без утвержденной государственной концепции роста производительности, привлечения правительственных организаций, научных, внедренческих и других общественных институтов. Как показала практика последних лет становления российской экономики, отсутствие на государственном уровне стратегии повышения производительности как в целом по стране, так и по отдельным отраслям и регионам намного замедляет эту работу. Снижение внимания экономистов к показателю производительности и совершенствованию методических подходов к его измерению обусловили практическое отсутствие научных исследований по развитию теории и практики к ее повышению, как главного фактора экономической стабильности на российских предприятиях, в учреждениях и организациях.

Влияние внутренних факторов повышения производительности определяется в основном деятельностью на корпоративном уровне управления. В отличие от традиционной для российских предприятий модели повышения производительности, направленной главным образом на управление производством, необходимо учитывать факторы повышения производительности присущие деятельности в условиях рыночной экономики. $K$ таким факторам следует отнести менеджмент в маркетинговой деятельности, управление финансами и расширение методов управления в производственной деятельности.

Реализация факторов повышения производительности в сфере маркетинга позволит снизить затраты при реализации продукции, потерь, связанных с изменением конъюнктуры рынка, потерь обусловленных излишними объемами выпускаемой продукции необходимых удовлетворению потребностей рынка и т. п.

Финансовый менеджмент будет способствовать повышению производительности за счет эффективного движения фиксированного капитала и натуральных ресурсов, сокращению издержек связанных с владением наличными средствами, использования ликвидных активов, совершенствованием финансового и управленческого учета.

Внутренние факторы повышения производительности, связанные с управлением производством, наиболее методически разработанное направление для корпоративного уровня управления в РФ, которые, тем не менее, требую модификации с учетом современных тенденций в развитии экономической деятельности. В методическом плане требуют разработки маркетинговые методы управления, способствующие снижению потерь при реализации продукции, связанные с продажами в зависимости от изменений рынка; стратегическое планирование, позволяющее отразить повышение производительности на снижение уровня риска и повышение жизнеспособности предприятия. Методы управления персоналом следует увязать

\section{Baikal Research Journal}


в части стимулирования работников с результатами роста производительности, а методы организации труда дополнить современными технологиями (5S, JIT, TPM и т. п.). Совершенствование управление контролем качества на протяжении цикла от создания продукции (услуги) до ее послепродажного обслуживания обеспечит при деятельности производственной системы ее гибкость и рост производительности. Управление финансами и наличными средствами на корпоративном уровне позволит сократить потребность в оборотном капитале, издержки, связанные с его наличием, обеспечить эффективное движение фиксированного капитала и натуральных ресурсов, унификацию финансового и управленческого учета. Реализация внутренних факторов повышения производительности требует не только готовности их применения, но и серьезного научного исследования по разработки рекомендаций их систематического внедрения на практике.

Сочетание внутренних и внешних факторов определяют направления деятельности по повышению производительности. В практической деятельности по повышению производительности эти направления обычно взаимосвязаны и не могут расширяться, дополняться и выступать в виде самостоятельных комплексных решений.

При формировании концепции роста производительности немаловажное значение играет создание единой по стране системы, включающей органы управления, их функции, принципы взаимодействия организационных форм деятельности, ресурсное обеспечение на всех уровнях управления - федеральном, региональном, муниципальном, отраслевом и корпоративном.

Поскольку проблемы производительности касаются всего общества и служат главной цели - повышению уровня жизни населения, то достижение ее наивысшего показателя касается взаимосвязанной деятельности всех уровней управления. На уровне национальной экономики целью роста производительности будет увеличение валового национального продукта и дохода на душу населения. На отраслевом и региональном уровнях управления производительность определяет их конкурентоспособность и служит критерием качества жизни работников отрасли и региона. Рост производительности на корпоративном уровне способствует в первую очередь успешной работе предприятия или учреждения, созданию новых рабочих мест и повышению заработной платы работников.

Таким образом, цели увеличения производительности на различных уровнях управления экономикой страны взаимосвязаны и должны рассматриваться как национальная идея развития общества, начиная с федерального уровня управления и кончая конкретным рабочим местом. Организационная структура управления ростом производительности в РФ, включающая органы управления, координирующие структуры, механизм реализации и исполнительные учреждения и организации рассматривалась в научной литературе [8, с. 22]. Отказ от командно-административных методов работы существенно изменил роль и влияние федеральных и региональных органов управления на уровень самостоятельности организаций в экономическом развитии. Вместе с тем, именно государство должно определить основные направления и темпы экономического роста страны, в том числе и темпы прироста производительности.

Государственная долгосрочная стратегия повышения производительности обосновывает необходимость принятия долгосрочной государственной программы, позволяющей концентрировать людские, финансовые и др. виды ресурсов на приоритетных направлениях, обеспечивающих стабилизацию производства, стимулирование деловой активности предприятий и достижение запланированных темпов прироста добавленной стоимости и производительности. Основные мероприятия государственной программы повышения производительности должны сформировать

\section{Baikal Research Journal}

электронный научный журнал Байкальского государственного университета 
комплекс мер научно-исследовательского, производственного, социально-экономического, организационного характера, увязанных по ресурсам, срокам и исполнителям. Государственная программа может быть ориентирована на ближайшую и среднесрочную перспективу, поскольку задача на 2-3 летний период состоит в стабилизации производства, активизации и стимулировании деловой и производственной предпринимательской деятельности, создавая правовые, экономические и организационные условия для осуществления этой работы. Особое место в государственной программе должно принадлежать кадровому, научно-методическому, нормативному и информационному обеспечению повышения производительности. Государственная программа повышения производительности должна конкретизироваться в отраслевых и региональных (муниципальных) государственных программах, с указанием ежегодных темпов прироста производительности по каждому объекту управления. Не менее важным показателем работы над проблемами повышения производительности в РФ должна стать организация в стране движения за производительность и международное сотрудничество с зарубежными ассоциациями, фондами и фирмами, обладающими опытом в этой работе.

Рассмотренные проблемы повышения производительности в России важны не только для обеспечения темпов роста экономического развития и валового внутреннего продукта. Их решение позволит специалистам предприятий определить стратегию своего развития, а органам регионального и муниципального управления обеспечить повышение показателей социального развития.

\section{Список использованной литературы}

1. Соколова Л. Г. Производительность: теория, измерение, проблемы роста / Л. Г. Соколова. - Иркутск : Изд-во ИГЭА, 2000. - 241 с.

2. Силакшин С. С. Государственное управление в России и труд. Оплата, мотивация, производительность : монография / С. С. Силакшин, В. Э. Багдасарян, И. Ю Колесник. М. : Науч. эксперт, 2010. - 248 с.

3. Соколова Л. Г. Теоретико-методологические подходы к оценке результативности и әффективности труда в системе государственного управления / Л. Г. Соколова // Публичное управление и территориальное развитие: тенденции, проблемы, перспективы и последствия мирового кризиса : сб. материалов Междунар. науч.-практ. конф. / отв ред. Е. А. Колодина. - Иркутск : Изд-во БГУЭП, 2015. - 156 с.

4. Федченко А. А. Методические подходы к исследованию производительности труда / А. А. Федченко // Экономика труда. — 2016. - T. 3, № 1. - C. 41-62. DOI: 1018334/ et.3.1.35153.

5. Kurosava K. Structural approach to the concept and measurement of productivity (2) / K. Kurosava // Keize Shishi: Econimic Journal of Nichon University. — 1980. — Vol. 50, № 2. - P. 96-135.

6. Соколова Л. Г. Новый взгляд на производительность: методика оценки общей произ водительности / Л. Г. Соколова. - Иркутск : Изд-во БГУЭП, 2002. - 184 с.

7. Соколова Л. Г. Методология расчета производительности управленческого труда / Л. Г. Соколова // Известия Иркутской государственной экономической академии. 2016. - T. 26, № 2. - C. 213-219. - DOI : 10.17150/1993-3541.2016.26(2).213-219.

8. Соколова Л. Г. Управление производительностью труда на различных уровнях хозяйствования : автореф. дис. ... д-ра экон. наук : 08.00.05 / Л. Г. Соколова. - Иркутск, 2004. - 30 c.

\section{References}

1. Sokolova L. G. Proizvoditel'nost': toriya, izmerenie, problemy rosta [Efficiency: Issues of Theory, Measurement, Growth]. Irkutsk State Academy of Economics Publ., 2000. 241 p.

2. Silakshin S. S., Bagdasaryan V. E., Kolesnik I. Yu. Gosudarstvennoe upravlenie v Rossii i trud. Oplata, motivatsiya, proizvoditel'nost' [Public administration in Russia and labor. Payment, motivation, productivity]. Moscow, Nauchnyi ekspert Publ., 2010. 248 p.

\section{Baikal Research Journal}

электронный научный журнал Байкальского государственного университета 
3. Sokolova L. G. Theoretical and methodological approaches to assessing performance and efficiency of labor in public administration system. Kolodina E. A. (ed.). Publichnoe upravlenie $i$ territorial'noe razvitie: tendentsii, problemy, perspektivy i posledstviya mirovogo krizisa. Materialy Mezhdunarodnoi nauchno-prakticheskoi konferentsii [Public Governance and Territorial Development: Trends, Problems, Prospects and Consequences of the Global Crisis. Materials of International Research Conference]. Irkutsk, Baikal State University of Economics and Law Publ., 2015. 156 p.

4. Fedchenko A. A. Methodological approaches to studying labor productivity. Ekonomika truda = Labor Economics, 2016, vol. 3, no. 1, pp. 41-62. DOI: 1018334/et.3.1.35153. (In Russian).

5. Kurosava K. Structural approach to conception and measurement of productivity (2). Keize Shishi: Econimic Journal of Nichon University, 1980, vol. 50, no. 2, pp. 96-135. (In Russian).

6. Sokolova L. G. Novyi vzglyad na proizvoditel'nost': metodika otsenki obshchei proizvoditel'nosti [A fresh approach to productivity: method of assessing general productivity]. Irkutsk, Baikal State University of Economics and Law Publ., 2002. 184 p.

7. Sokolova L. G. Calculation methodology for management performance evaluation. Izvestiya Irkutskoi gosudarstvennoi ekonomicheskoi akademii = Bulletin of Irkutsk State Economics Academy, 2016, vol. 26, no. 2, pp. 213-219. DOI: 10.17150/1993-3541.2016.26(2).213-219. (In Russian).

8. Sokolova L. G. Upravlenie proizvoditel'nost'yu truda na razlichnykh urovnyakh khozyaistvovaniya. Avtoref. Dokt. Diss. [Labot productivity management at various levels of economic management . [Doct. Diss. Thesis]. Irkutsk, 2004. 30 p.

\section{Информация об авторе}

Соколова Лариса Георгиевна - доктор экономических наук, профессор, кафедра экономики и государственного управления, Байкальский государственный университет, 664003, г. Иркутск, ул. Ленина, 11; e-mail: sokolova-lg@yandex.ru.

\section{Author}

Larisa G. Sokolova - Doctor habil. (Economics), Professor, Chair of Economics and Public Administration, Baikal State University, 11 Lenin St., 664003, Irkutsk, Russian Federation; e-mail: sokolova-lg@yandex.ru.

\section{Библиографическое описание статьи}

Соколова Л. Г. Концепция роста производительности в Российской Федерации / Л. Г. Соколова // Baikal Research Journal. - 2017. - T. 8, № 2. — DOI: 10.17150/2411$\underline{6262.2017 .8(2) .25 .}$

\section{Reference to article}

Sokolova L. G. Conception of productivity increase in the Russian Federation. Baikal Research Journal, 2017, vol. 8, no. 2. DOI: 10.17150/2411-6262.2017.8(2).25. (In Russian).

\section{Baikal Research Journal}

